\title{
STREPTOCOCCI IN CHRONIC RESPIRATORY INFECTIONS
}

\author{
W. Ray Hodge and Cecile Cohen \\ From the Connanght Antitoxin Laboratories, Reseurch Division, University of Toronto, \\ Toronto, and the Laboratory Division of the Chest Clinic of the Deparimewt \\ of Soldier's Civil Resstablishment
}

The clinical material for the present study was made available through the Chest Clinic of the Department of Soldiers' Civil Reestablishment at Toronto. Ideal conditions for repeated examinations of sputum were obtained as many of the cases were pensioners returning for periodic examination and many were attending for vaccine treatment, while others still were held in observation wards for varying periods of time.

The chief aim of the study was to determine the constancy or inconstancy of types of streptococci occurring in chronic nontuberculous respiratory infections. In the determination of this first objective, many points of interest occurred and many questions of doubt arose, necessitating extensive collateral investigations; the apparently simple problem proved complex and an attempt was made to solve questions of doubt by frequent specially conducted experiments which are incorporated in this paper. It was hoped that strains constantly present on closely repeated examinations of sputum might be isolated; that vaccines might be prepared from strains so isolated, and that in this way vaccine treatment might be rendered less haphazard and the results more uniformly encouraging. Roughly, our idea was to examine three samples of sputum collected at two day intervals from selected cases. The cases of bronchial asthma in this series include only those which failed to show any evidence of sensitization with extensive percutaneous protein tests. Streptococci in these samples were to be identified by Brown's method of classification. The choice of this classification was made chiefly because of convenience and uniformity of terminology; and though at first sight somewhat confusing and complicated was justified by the ease with which the flora in various samples of sputum from the same source could be compared. The effect of vaccine therapy on the patient and on the streptococcal flora was to be observed. The numerous sidepaths of investigation have, however, prevented the fulfilment of this aim; it soon became apparent

Received for publication Nov. 25, 1921. 
that the streptococcal flora in these cases was not simple, and that the preparation of vaccines by the suggested method would be too laborious. Accordingly, attention was finally focused on the flora alone and an attempt made to discover precisely how complex this aspect of the problem was.

\section{METHODS}

The streptococcal reactions in blood agar were determined by the use of Brown's ${ }^{1}$ standard deep plates substituting citrated human blood for defibrinated horse blood. Repeats made with citrated human and defibrinated horse blood were found to give parallel results. In blood agar the organisms were thus identified as falling into one of 4 types: beta (complete hemolysis), alpha prime (partial hemolysis), alpha (green production), and gamma (no change). For further identification the fermentative reactions were determined in the 6 carbohydrates: mannite, lactose, salicin, raffinose, inulin, and saccharose. The information obtained in this way was used to place the organisms in Brown's classification. In this classification streptococci are placed according to types in blood agar: groups, with respect to fermentation of mannite, lactose and salicin; and subgroups, with respect to fermentation of saccharose, inulin and raffinose. The types are alpha, alpha prime, beta and gamma; the groups are numbered 1 to 8 , and the subgroups 0.1 to 0.8 , inclusive. By this means the hemolytic and fermentative properties of a streptococcus can be referred to by a letter, a number, and a decimal. Hence a 1.2 indicates a green-producing streptococcus which ferments lactose, salicin, saccharose and raffinose, but does not ferment mannite or inulin. This classification was found to be very convenient for the work in hand for the reasons mentioned. It is, however, unfortunately handicapped because of the confusion attending such a complete revolution in terminology. It should be emphasized that this classification in many instances simply introduces new terms for streptococcus groups already known under more familiar name. For instance, a beta type streptococcus simply means a strongly hemolytic streptococcus; an alpha type streptococcus is what is characterized as Streptococcus viridans in ordinary terminology.

$\begin{array}{rll}\text { Thus } & \beta 1.1 \text { is } \mathrm{S} \text {. pyogenes } & \text { (Rosenbach) } \\ \beta & 2.1 \text { is } \mathrm{S} \text {. anginosus } & \text { (Andrews and Horder) } \\ \beta & 3.1 \text { is } \mathrm{S} \text {. equi } & \text { (Schultz) } \\ \beta & 4.1 \text { is } \mathrm{S} \text {. subacidus } & \text { (Holman) }\end{array}$

1 Use of Blood Agar for Study of Streptococci, Rockefeller Monograph 9. 

$\beta 5.1$ is $\mathrm{S}$. infrequens
$\beta 7.1$ is $\mathrm{S}$. alactosus
a 1.1 is $\mathrm{S}$. mitis
a 2.1 is $\mathrm{S}$. salivarius
a 3.1 is $S$. equinus
a 4.1 is $\mathrm{S}$. ignavus
a 5.1 is $\mathrm{S}$. fecalis

(Holman)

(Smith and Brown)

(Andrews and Horder)

(Andrews and Horder)

(Andrews and Horder)

(Holman)

(Andrews and Horder)

\section{TECHNIC}

Particles of sputum were washed twice in sterile saline, planted in serum broth, and after 6 hours' incubation, a loopful of this broth culture was plated on blood agar. After 24 hours' incubation single colonies were picked and streaked on the surface of blood agar and after further incubation, the culture so obtained was planted in a tube of serum broth; after 18 hours' incubation a loopful of properly diluted broth culture was sown in deep blood agar plates. Care was taken to have the agar cooled to $45 \mathrm{C}$. before the blood was added, thus preventing hemolysis due to heat. From the deep plate single colonies were picked under the microscope, carved out with a wire loop and emulsified in a tube of broth (beef infusion broth $P_{H} 7.6$ with 3 or 4 drops of sterile, citrated human blood added to each tube). After 18 hours, films were made and the appearance noted. The blood broth culture, in which growth was invariably heavy, was used for seeding the sugar tubes. Medium for fermentations was beef infusion broth, $P_{H} 7.6$ previously fermented with $B$. coli and so rendered sugar-free. The reaction was adjusted colorimetrically and checked by electrolytic methods. Electrolytic determinations were done by $\mathrm{Mr}$. Moloney of the Connaught Laboratories. The sugars were dry sterilized, suspended in thin glass bulbs ${ }^{2}$ over a small amount of water in a flask; the water contained sufficient Andrade's indicator for final concentration of $1 \%$. These flasks were sterilized in the autoclave for half an hour at 15 pounds. After sterilization the glass bulbs were broken against the bottom of the flasks and the sugars dissolved. The sugar and indicator was added to the sugar-free broth, to which $10 \%$ sterile horse serum had been added. The completed fermentation medium was poured into a sterile funnel covered with sterile gauze and tubed through a hooded pipet. In this way a second sterilization of the sugar was avoided. The tubes were paraffined and incubated

\footnotetext{
2 A method devised by Dr. D. T. Fraser of these laboratories to prevent hydrolysis of the sugars.
} 
for 48 hours and those not contaminated stored in the ice-chest until required. Contanination of any of the tubes was infrequent. Mediums so prepared with a final PH of 7.6 and stored in the ice-chest for eight months showed a $P_{H}$ of 7.42. The seeded fermentation tubes were incubated for 6 days at $37 \mathrm{C}$. and the results read. Films invariably revealed good growth.

In the preliminary work, using these methods, it was found that sputum collected at 2 or 3 day intervals from the same source showed marked variations in the strains isolated. It was not possible to pick out any particular strain which occurred in succeeding samples and which might be considered pathogenic on account of the constancy of its appearance. It seemed possible that this might be due to three causes: (1) inaccuracy of the methods employed or inconstancy of appearance of organisms on blood agar or inconstancy of fermentations; (2) an insufficient number of organisms were being picked from the preliminary plates so that the determination of flora present was haphazard; ( $\overline{3})$ an actual variation in flora from day to day. These three possible causes were investigated in detail and the results obtained form the bulk of the material of this paper.

Owing to lack of space it is not possible to give in detail the work dealing with the accuracy of these methods. Briefly, we found that under constant conditions the appearance produced in blood agar was constant. An interesting variation was encountered in certain alpha prime strains $\left(a^{\prime} 2.1\right)$; it was found that in lightly seeded plates the alpha prime appearance was constantly produced. In heavily seeded plates, however (over 200 colonies), these organisms produced green zones and on repeated refrigeration and incubation alternate green and hemolytic rings. The fermentations were found to be rather less accurate. Lyall ${ }^{3}$ found that on repetition less than $5 \%$ of his strains showed variations. Holman ${ }^{4}$ has pointed out that supposed variations in fermentative reactions may be due to the use of inferior mediums. Streptococci grew well in our sugar-free broth before the addition of carbohydrate. One hundred strains after storage were replated for purity, and the fermentative reactions determined with variations in 10 strains. There were 2 apparent types of variation; (a) certain alpha and alpha prime strains, although showing quite good growth, failed to ferment a sugar which they had fermented previously. In these instances by increasing the amount of seed

3 Jour. Med. Research, 1914, 30, p. 487.

- Ibid., 1916, 35, 1. 151. 
culture and producing abnormally heavy growth fermentation resulted. This was evidently a marginal type of fermentation. (b) Certain bèta strains seemed to lose completely their power to ferment certain sugars -this latter finding is in agreement with Clawson ${ }^{5}$ who found considerable variation on repeated titrations of certain strains of hemolytic streptococci after storage. We found that repeated subculture in the sugar showing variation leads to greater ease of fermentation of this sugar.

Having determined that the methods employed were sufficiently accurate, the remaining two possibilities were investigated, namely, the possibility of an extensive flora and the possibility of a daily variation in the strains present. Walker and Adkinson ${ }^{6}$ investigated the sputum of patients. with bronchial asthma and concluded that the thick sputum of these cases, provided it was washed, contained few types of streptococci. The classification adopted by these authors was that suggested by Holman. It should be remembered that in the present work Brown's classification was used throughout and that the possible number of variations in this classification is much greater than in that of Holman.

\section{INVESTIGATION OF VARIATIONS IN FLORA}

The early experiments of this part of the investigation cannot be given in detail. It was necessary first of all to reassure ourselves that the colonies were picked clean from the surface plates and that the cultures in the deep plates were pure. This was carefully checked, and the results showed that the strains were pure in every instance. We were now in a position to proceed with the problem in hand the early work at this stage soon showed an occasional marked variation in flora in succeeding samples of sputum collected at short intervals from the same source. Such a variation is shown in table 1. In these samples the sputum was surface plated in 4 ways. Direct particle, wash saline, 6-hour broth and 24-hour broth.

Here the variation of flora in the first and second specimens is marked. One cannot pick out any strain which occurs in considerable numbers in both specimens. There are no beta organisms in the first specimen, but a beta organism appears several times in the second specimen. Has the flora actually changed so considerably in three days or have the variations in flora not been exhausted in each sample?

6 Jour. Infect. Dis., 1920, 26, p. 93.

- Jour. Med. Research, 1919, 40, p. 229. 
The next experiment is an attempt to answer this question. Here the number of organisms picked from the surface plates was greatly increased, in this way an attempt was made to exhaust completely the variations in flora in the various samples examined.

TABLE 1

Chronic Bronchitis. Streptococci from Samples of Sputum Collected at Two DAY INTERVAISS

\begin{tabular}{|c|c|c|}
\hline \multirow{2}{*}{ Material Plated } & \multicolumn{2}{|c|}{ Specimen } \\
\hline & 1 & 2 \\
\hline $\begin{array}{l}\text { Washed } \\
\text { Direct } \\
\text { Particle }\end{array}$ & $\begin{array}{l}\text { Alpha } 2.4 \\
\text { Alpha } 1.2 \\
\text { Alpha } 6.1 \\
\text { Alpha' } 2.3 \\
\text { Alpha' } 2.1\end{array}$ & $\begin{array}{r}\text { I3eta } 1.1 \times 2 \\
\text { Alpha } 1.5 \\
\text { Alpha 1.2 } \\
\text { Alpha } 3.1 \\
\text { Gamma } 3.1\end{array}$ \\
\hline $\begin{array}{l}\text { Wash } \\
\text { Saline }\end{array}$ & $\begin{array}{l}\text { Alpha } 6.1 \times 2 \\
\text { Alpha' } 2.1\end{array}$ & $\begin{array}{r}\text { Beta } 1.1 \times 2 \\
\text { Alpha } 1.1 \\
\text { Alpha } 1.2 \\
\text { Gamma } 1.2\end{array}$ \\
\hline Broth, 6 hours incubation & $\begin{array}{l}\text { Alpha } 1.2 \\
\text { Alpha' } 2.1 \times 2 \\
\text { Alpha' } 3.1 \times 4\end{array}$ & $\begin{array}{r}\text { Alpha } 1.2 \\
\text { Alpha' } 3.1 \\
\text { Gamma } 1.2\end{array}$ \\
\hline Broth, 24 hours incubation & Alpha' $3.1 \times 3$ & $\begin{aligned} \text { Beta } 1.1 \\
\text { Alpha' } 3.1 \\
\text { Alpha } 3.1 \\
\text { Alpha } 1.2 \times 2\end{aligned}$ \\
\hline
\end{tabular}

TABLE 2

Bronchial asthma. One Hundred and Twelve Different Streptococci Isolated from Four Samples of Sputum Showing Types Isolated FROM VARIOUS SAMPLES

\begin{tabular}{|c|c|c|c|}
\hline \multicolumn{4}{|c|}{ Sputum Sample } \\
\hline 1. $7 / 12 / 20$ & 2. $18 / 12 / 20$ & 3. $27 / 1 / 21$ & 4. $31 / 1 / 21$ \\
\hline $\begin{array}{l}\text { Total number of } \\
\text { strains........ } 18 \\
\text { Number of djffer- } \\
\text { ent types....... } 11\end{array}$ & $\begin{array}{l}\text { Total number of } \\
\text { strajns....... } 22 \\
\text { Number of differ- } \\
\text { ent types...... } 8\end{array}$ & $\begin{array}{r}\text { Total number of } \\
\text { strains........ } 39 \\
\text { Number of differ- } \\
\text { ent types....... } 8\end{array}$ & $\begin{array}{l}\text { Total number of } \\
\text { strains........ } \\
\text { Number of differ- } \\
\text { ent types....... }\end{array}$ \\
\hline $\begin{array}{r}\text { Beta } 1.1 \times 2 \\
\text { Beta } 2.2 \times 1 \\
\text { Alphar } 2.1 \times 5 \\
\text { Alpha' } 2.2 \times 1 \\
\text { Alpha } 1.1 \times 2 \\
\text { Alpha } 1.2 \times 1 \\
\text { Alpha } 1.3 \times 1 \\
\text { Alpha } 2.1 \times 1 \\
\text { Alpha } 2.2 \times 2 \\
\text { Alpha } 3.3 \times 1 \\
\text { Gamma } 5.4 \times 1\end{array}$ & $\begin{array}{r}\text { Beta } 2.1 \times 2 \\
\text { Alpha } 2.1 \times 4 \\
\text { Alpha } 1.1 \times 2 \\
\text { Alpha } 1.2 \times 3 \\
\text { Alpha } 2.1 \times 6 \\
\text { Alpha } 2.2 \times 3 \\
\text { Alpha } 3.1 \times 1 \\
\text { Gamma } 1.1 \times 1\end{array}$ & $\begin{array}{r}\text { Beta } 2.1 \times 4 \\
\text { Beta } 3.1 \times 1 \\
\text { Alphar } 1.1 \times 2 \\
\text { Alpha } 2.1 \times 5 \\
\text { Alpha } 1.1 \times 6 \\
\text { Alpha } 1.2 \times 8 \\
\text { Alpha } 2.1 \times 7 \\
\text { Alpha } 2.2 \times 6\end{array}$ & $\begin{array}{r}\text { Beta } 2.1 \times 1 \\
\text { Beta } 3.1 \times 1 \\
\text { Alpha' } 1.1 \times 3 \\
\text { Alpha' } 2.1 \times 2 \\
\text { Alpha' } 5.1 \times 2 \\
\text { Alpha } 1.1 \times 10 \\
\text { Alpha } 1.2 \times 8 \\
\text { Alpha } 1.3 \times 2 \\
\text { Alpha } 2.1 \times 3 \\
\text { Alpha } 2.2 \times 1\end{array}$ \\
\hline
\end{tabular}

In table 2 are shown the results obtained by picking large numbers of colonies from the preliminary plates; four different samples of sputum from the same patient (a bronchial asthmatic) were examined. 
In this experiment 112 strains were isolated from 4 samples of sputum with 19 different types. Thirty-one strains were rechecked for appearance in blood agar and fermentation reactions with constant results. It will be seen that the flora appears fairly constant-the number of different types in various samples varies from 8 to 11 . The organism appearing most frequently is a 1.2. There are various beta and alpha prime types in each sample, and as far as these groups of the flora are concerned, the parallelism between samples 3 and 4 is almost complete, not quite so complete between samples 2 and 3 , or 2 and 4 , and still less complete between samples 1 and 2,1 and 3 , and

TABLE 3

Bronchial Asthma. One Hundred and Thirty-One Different Streptococci Isolated from Two Samples of Sputum, Showing Types Isolated from Two Samples

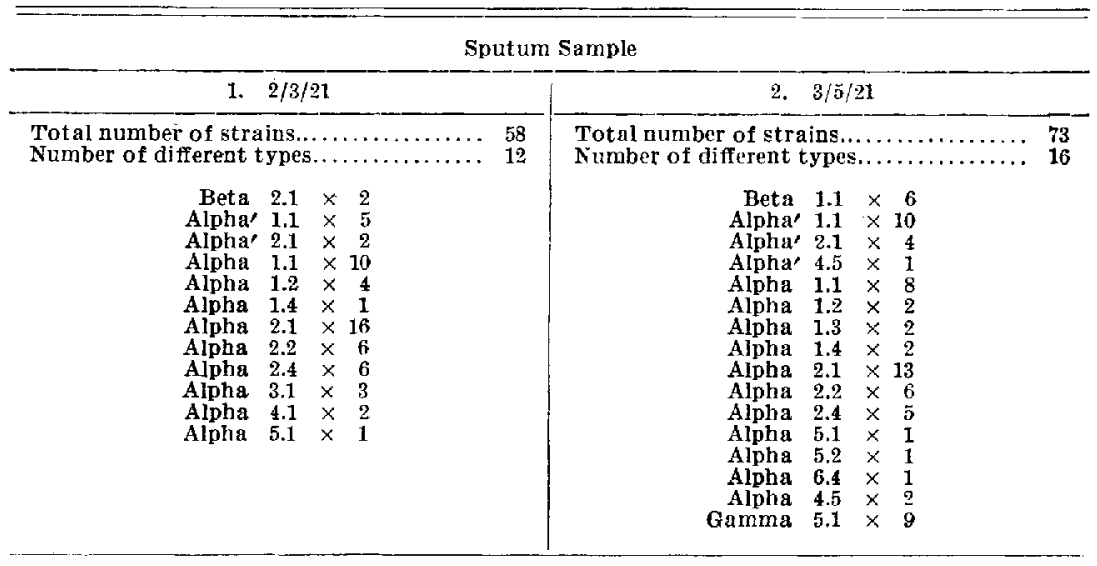

1 and 4. This probably indicates a gradual change in flora as samples 1 and 4 with the largest time interval (almost 2 months) show the most marked divergence of types, while samples 3 and 4 with only 4 days interval show almost complete parallelism. $a^{\prime} 2.1$, although not occurring as frequently as a 1.2 , occurs most persistently, from 4 to 5 times in each sample.

This experiment was repeated on the sputum of another patient with bronchial asthma. The results are shown in table 3 .

In this experiment 131 strains were isolated from 2 samples of sputum (with 2 days intervening) with 19 different types. The number of types in each sample varied from 12 to 16 . Here again there is an essential parallelism of types in the 2 samples, broken most conspicuously by the beta types, $\beta 2.1$ being recovered twice in sample 
1 , and $\beta 1.1$ being recovered 6 times in sample 2 . The variation in these beta types is of considerable interest; it is difficult to reconcile the variations in these types with the relatively high pathogenicity which they possess. As the agglutination results do not place these types in a single imnunologic group we can only conclude that these variations are real and that the beta group is at least not a supreme etiologic factor in these cases. The organism occurring most frequently in these samples is $\alpha 2.1$, and next in frequency a 1.1 .

The influence of the type of particle on the flora developed is shown in table 4.

It is immediately apparent that the flora does not vary appreciably in particles of different appearance in the same sample of sputum-the

TABLE 4

Bronchial Asthan. Flora in Three Different I'articles from the Shme SAMPIE OF SPUTUM

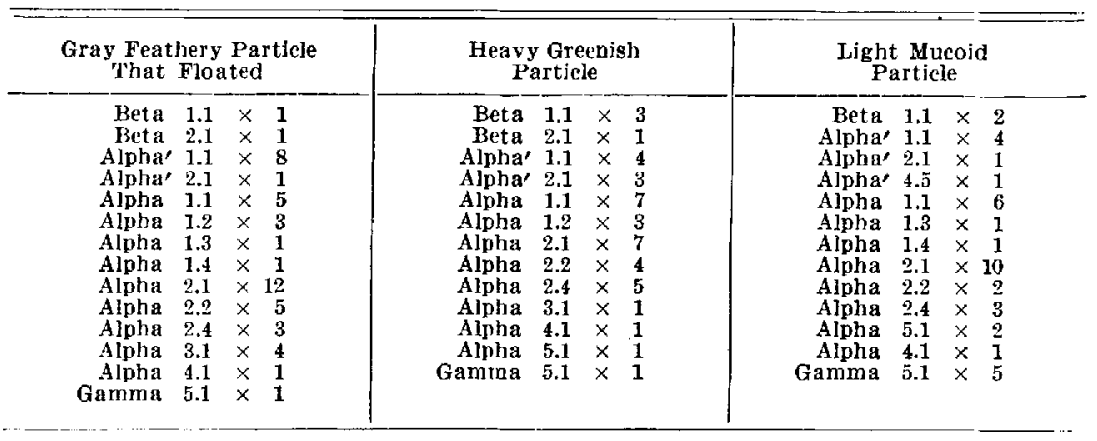

growth is apparently homogeneous throughout the sputum; hence the choice of particle has little effect on the flora ultimately developed in the culture.

The method of making the preliminary plate was similarly investigated. The results are shown in table 5 .

In table 5 it is seen that the 3 methods. employed give essentially parallel results. The beta organisms are not apparently overgrown by the alphas in a 24-hour broth culture. These observations have an important bearing on the method of preparation of vaccines.

It is obvious, from the results obtained by an exhaustive exploration. of the flora in these cases, that the classification adopted distinguished many different groups of streptococci in single specimens of sputum. The immunologic relationship of these various groups was a question of interest which we felt demanded investigation. The agglutination 
reaction was chosen as being the reaction most likely to bring out sharply the differences sought. Kligler ${ }^{7}$ found that there was a distinct parallelism between groups of streptococcr distinguished by fermentations and by agglutinations. He concluded that fermentation reactions tended to divide streptococci into broad, distinct species. Floyd and Wolbach ${ }^{8}$ found that agglutination reactions supported the value of fermentation tests. Dochez, Avery and Lancefield, in an investigation of hemolytic streptococci isolated during the course of an epidemic of bronchopneumonia, distinguished by the agglutination reaction 4 distinct types. They found that all members of their type $S_{b 0}$ fermented mannite. The agglutinations in the present work were undertaken

TABLE 5

Bronchial Asthma. Influence of Method of Plating on Flora Developed

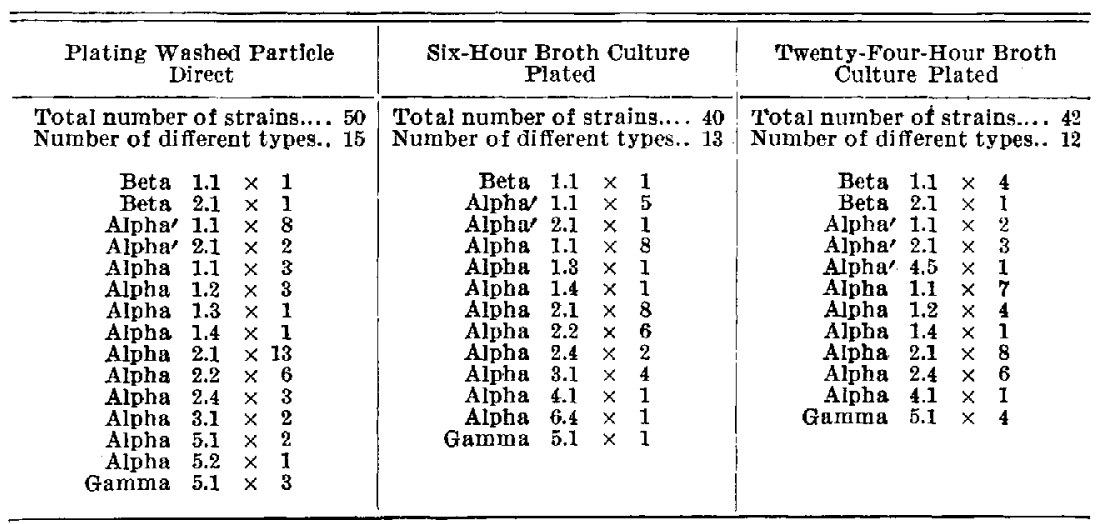

simply for the further elucidation of the problems we were trying to solve and not to attempt an immunologic classification of streptococci, hence relatively few animals were immunized.

\section{AGGLUTINATIONS}

Rabbits were immunized with 7 different strains of streptococci, all of which had been isolated from the sputum of the 2 patients with bronchial asthma, intensively investigated by the other methods. The immune serums obtained in this way were used for agglutinations with 62 strains from various specimens of sputum and one strain from a case of erysipelas.

7 Jour. Infect. Dis., 1915, 16, p. 327.

B Jour. Med. Research, 1913, 29, p. 493. 
TABLE 6

Results of Agglutination Tests

\begin{tabular}{|c|c|c|c|c|c|c|c|c|c|c|}
\hline \multirow{2}{*}{\multicolumn{2}{|c|}{ Strain number....... }} & \multicolumn{9}{|c|}{ Serums } \\
\hline & & \multirow{2}{*}{ 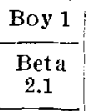 } & \multirow{2}{*}{$\frac{\text { Boy } 2}{\text { Beta }}$} & \multirow{2}{*}{$\left|\frac{\text { Day 1 }}{\mid \text { Alpha' }}\right|$} & \multirow{2}{*}{$\mid \begin{array}{c}\text { Boy } 3 \\
\text { Alpha: } \\
2.1\end{array}$} & \multirow{2}{*}{$\frac{\text { Boy } 4}{\underset{2.1}{\text { Alpha' }}}$} & \multirow{2}{*}{$\frac{\text { Boy } 5}{\substack{\text { Alpha } \\
1.1}}$} & \multirow{2}{*}{  } & \multirow{2}{*}{$\begin{array}{c}\text { Normal } \\
\text { Human } \\
\text { and Rab- } \\
\text { bit Serum }\end{array}$} & \multirow{2}{*}{$\begin{array}{l}\text { Con- } \\
\text { trol }\end{array}$} \\
\hline Classifica & tion........ & & & & & & & & & \\
\hline Dilutions & n............ & $1: 20$ & $1: 20$ & $1: 50$ & $1: 50$ & $1: 50$ & $1: 50$ & $1: 50$ & $1: 20$ & \\
\hline $\begin{array}{c}\text { Strain } \\
\text { Number }\end{array}$ & $\begin{array}{c}\text { Classif- } \\
\text { cation }\end{array}$ & $\begin{array}{l}1: 40 \\
1: 80\end{array}$ & $\begin{array}{l}1: 40 \\
1: 80\end{array}$ & $\begin{array}{l}1: 100 \\
1: 200\end{array}$ & $\begin{array}{l}1: 100 \\
1: 200\end{array}$ & $\begin{array}{l}1: 100 \\
1: 200\end{array}$ & $\begin{array}{l}1: 100 \\
1: 200\end{array}$ & & $\begin{array}{l}1: 40 \\
1: 80\end{array}$ & \\
\hline Boy 1 & Beta 2.1 & $\begin{array}{l}\mathrm{CA} \\
1: 80 \\
\mathrm{ACA} \\
1: 160 \\
\mathrm{SA} \\
1: 320\end{array}$ & - & - & - & 一 & - & - & - & - \\
\hline Boy 2 & Beta 1.1 & $\underline{-1.320}$ & $\begin{array}{l}C A \\
1: 320 \\
A C A \\
1: 640\end{array}$ & - & - & - & - & - & - & - \\
\hline Day 1 & Alpha' 3.1 & - & 1.040 & $\begin{array}{l}O A \\
1: 8000 \\
\mathbf{S A} \\
1: 64,000\end{array}$ & - & - & - & - & - & - \\
\hline Boy 3 & Alpha' 2.1 & $1: 400$ & $\begin{array}{l}C A \\
1: 200 \\
A C A \\
1: 400\end{array}$ & $1: 1600$ & $\begin{array}{l}\mathrm{CA} \\
1: 12,000\end{array}$ & $\begin{array}{c}\mathrm{CA} \\
1: 12,800\end{array}$ & $\begin{array}{l}\text { CA } \\
1: 5120\end{array}$ & $1: 80$ & - & - \\
\hline Boy 4 & Alpha' 2.1 & $1: 400$ & $\begin{array}{l}\mathrm{CA} \\
1: 200 \\
\mathrm{ACA} \\
1: 400\end{array}$ & $1: 1600$ & $\begin{array}{c}\mathrm{CA} \\
1: 12,000\end{array}$ & $\begin{array}{l}\text { CA } \\
1: 12,800\end{array}$ & $\begin{array}{l}\mathrm{CA} \\
1: 5120\end{array}$ & $1: 80$ & - & - \\
\hline Boy 5 & Alpha 1.1 & - & - & - & - & - & $\begin{array}{l}\text { CA } \\
1: 3200 \\
\text { ACA } \\
1: 5120\end{array}$ & - & - & - \\
\hline Boy 6 & Alpha 2.2 & - & - & - & - & - & 1.0120 & $\begin{array}{l}\mathrm{OA} \\
1: 400 \\
\mathrm{SA} \\
1: 800\end{array}$ & - & - \\
\hline $\begin{array}{l}\text { Boy } 7 \\
\text { Boy } 8\end{array}$ & $\begin{array}{l}\text { Alpha' } 5.1 \\
\text { Alpha' } 1.1\end{array}$ & - & - & $\overline{-}$ & - & $\bar{z}$ & - & - & - & - \\
\hline Boy 9 & Alpha 1.1 & - & - & $\bar{z}$ & $\bar{z}$ & $\bar{z}$ & $\bar{z}$ & $\underline{-}$ & $=$ & $\bar{z}$ \\
\hline Boy 10 & Alpha 1.2 & - & - & - & - & - & - & $=$ & - & $=$ \\
\hline $\begin{array}{l}\text { Boy } 11 \\
\text { Boy } 12\end{array}$ & Alpha' 1.1 & $\overline{-}$ & $\overline{-}$ & - & $\overline{-}$ & $\overline{-}$ & - & $\bar{z}$ & $=$ & - \\
\hline $\begin{array}{l}\text { Boy } 12 \\
\text { Boy } 13\end{array}$ & $\begin{array}{ll}\text { Beta } & 3.1 \\
\text { Beta } & 2.1\end{array}$ & $\overline{+}$ & $\bar{t}$ & $\overline{+}$ & $\bar{I}$ & $\bar{t}$ & $\overline{+}$ & - & $\overline{+}$ & $\vec{t}$ \\
\hline Boy 14 & Alpha' 2.1 & + & + & + & + & + & + & + & - & - \\
\hline Boy 15 & Alphar 2.1 & + & + & + & + & + & + & + & - & - \\
\hline $\begin{array}{l}\text { Boy } 16 \\
\text { Boy } 22\end{array}$ & $\begin{array}{l}\text { Alpha } a^{\prime} .1 \\
\text { Alph }\end{array}$ & $\begin{array}{l}+H \\
+I I\end{array}$ & $\begin{array}{l}+\mathrm{H} \\
+\mathrm{H}\end{array}$ & $t_{H}$ & + & + & + & + & - & - \\
\hline $\begin{array}{l}\text { Boy } 22 \\
\text { Boy } 25\end{array}$ & $\begin{array}{l}\text { Alpha' } 2.1 \\
\text { Alpha' } 2.1\end{array}$ & $+\mathbf{H}$ & $+\mathbf{H}$ & $+\mathbf{H}$ & $+\mathrm{H}$ & $+\mathrm{H}$ & $\stackrel{+}{+} \mathrm{H}$ & + & $\overline{-}$ & $\overline{-}$ \\
\hline Boy 26 & Alpha 1.1 & - & - & $\rightarrow$ & - & - & + & - & - & - \\
\hline Boy 19 & Alpha 1.1 & - & - & - & - & - & + & & - & - \\
\hline Boy 17 & Alpha' 1.1 & 二 & - & - & 二 & - & 二 & & & - \\
\hline $\begin{array}{l}\text { Boy } 18 \\
\text { Boy } 20\end{array}$ & $\begin{array}{l}\text { Alpha } 1.2 \\
\text { Alpha } 1.3\end{array}$ & 二 & $\bar{z}$ & 二 & $=$ & $\bar{z}$ & 二 & & & - \\
\hline Boy 21 & A]pha 2.2 & - & - & - & - & - & - & $1: 80$ & & $=$ \\
\hline Boy 23 & Alpha 2.1 & - & - & - & - & - & - & & - & - \\
\hline Boy 24 & Beta 2.1 & \pm & - & - & - & 一 & - & : & - & - \\
\hline Day 2 & Alpha' 3.1 & - & - & + & - & - & - & & & - \\
\hline Day 3 & Alpha' 3.1 & - & - & + & $=$ & $=$ & $=$ & & & - \\
\hline Day 4 & Alpha' 3.1 & $\overline{-}$ & $\bar{Z}$ & $+t_{+}^{H}$ & $\bar{I}$ & 二 & $\overline{-}$ & & & $=$ \\
\hline $\begin{array}{l}\text { Day } \\
\text { Day } 6\end{array}$ & $\begin{array}{l}\text { Alpha' } 3.1 \\
\text { Alpha' } 3.1\end{array}$ & $=$ & - & $+\mathrm{H}$ & - & - & - & & & $=$ \\
\hline Day 7 & Alpha 3.1 & - & - & + & - & - & - & & & - \\
\hline Day 8 & Alpha' 3.1 & - & - & + & - & - & - & & & - \\
\hline Day 9 & Alpha 2.1 & - & - & $\frac{1}{-}$ & - & - & - & & & - \\
\hline Day 10 & Beta 1.1 & - & - & \pm & - & - & - & & & - \\
\hline Day 11 & Beta 1.1 & - & - & \pm & - & - & - & & & \\
\hline Day 12 & Alpha' 2.1 & + & + & + & + & + & + & - & + & + \\
\hline
\end{tabular}


TABLE 6-Continued

Results of Agglutination Tests

\begin{tabular}{|c|c|c|c|c|c|c|c|c|c|c|}
\hline & & \multicolumn{9}{|c|}{ Serums } \\
\hline \multicolumn{2}{|c|}{ Strain number....... } & Boy 1 & Boy 2 & Day 1 & Boy 3 & Boy 4 & Boy 5 & Boy 6 & Normal & $\mathrm{COn}-$ \\
\hline \multicolumn{2}{|c|}{ Classifleation......... } & $\begin{array}{c}\text { Beta } \\
2.1\end{array}$ & $\begin{array}{c}\text { Beta } \\
1.1\end{array}$ & $\begin{array}{c}\text { Alpha' } \\
3.1\end{array}$ & $\underset{2.1}{\text { Alpha' }}$ & $\underset{2.1}{\text { Alpha }}$ & $\underset{1.1}{\text { Alpha }}$ & $\underset{2.2}{\text { Alpha }}$ & $\begin{array}{l}\text { and Rab- } \\
\text { bit Serum }\end{array}$ & trol \\
\hline \multicolumn{2}{|c|}{ Dilutions............ } & \multirow{2}{*}{$\begin{array}{l}1: 20 \\
1: 40 \\
1: 80\end{array}$} & \multirow{2}{*}{$\begin{array}{l}1: 20 \\
1: 40 \\
1: 80\end{array}$} & \multirow{2}{*}{$\begin{array}{l}1: 50 \\
1: 100 \\
1: 200\end{array}$} & \multirow{2}{*}{$\begin{array}{l}1: 50 \\
1: 100 \\
1: 200\end{array}$} & \multirow{2}{*}{$\begin{array}{l}1: 50 \\
1: 100 \\
1: 200\end{array}$} & \multirow{2}{*}{$\begin{array}{l}1: 50 \\
1: 100 \\
1: 200\end{array}$} & \multirow[t]{2}{*}{$1: 50$} & \multirow{2}{*}{$\begin{array}{l}1: 20 \\
1: 40 \\
1: 80\end{array}$} & \\
\hline $\begin{array}{l}\text { Strain } \\
\text { Number }\end{array}$ & $\begin{array}{c}\text { Classifl- } \\
\text { cation }\end{array}$ & & & & & & & & & \\
\hline SMP 1 & Alpha 2.2 & - & - & - & - & - & - & - & - & - \\
\hline $\begin{array}{l}\text { SMJ } 2 \\
\text { SHJ } 3\end{array}$ & Alpha 2.1 & $\pm \mathrm{H}$ & $\pm \mathbf{H}$ & $+\mathbf{H}$ & $\pm \mathbf{H}$ & \pm & $+\mathrm{H}$ & & & - \\
\hline SMJ 4 & $\begin{array}{ll}\text { Alphas } & 1.1 \\
\text { Alpha } & 2.1\end{array}$ & $=$ & $\overline{-}$ & $\overline{-}$ & $=$ & $\overline{-}$ & \pm & $\overline{-}$ & & $\overline{-}$ \\
\hline SMJ 5 & Alpha 2.1 & $\longrightarrow$ & - & - & - & - & - & & & 二 \\
\hline SMJ 6 & Alpha' 1.1 & - & - & - & - & - & $一$ & & & - \\
\hline SMJ 7 & Alpha 2.1 & - & - & - & - & - & - & & & - \\
\hline Kel 1 & Alpha' 5.1 & - & - & - & - & - & - & & & - \\
\hline Kel 2 & Alpha' 1.1 & - & - & - & - & - & - & & & - \\
\hline McAl 1 & Beta 3.1 & - & - & - & - & - & - & & & - \\
\hline MeAl z & Alpha 1.2 & - & - & - & - & - & - & & & - \\
\hline $\mathrm{SC} 2$ & Beta 3.1 & - & - & - & - & - & - & & & - \\
\hline S.Frysip. & Beta 1.1 & - & - & 一 & - & - & - & & & - \\
\hline Car 2 & Alpha' 2.1 & + & $+\mathbf{H}$ & $+\mathbf{H}$ & + & + & + & & & - \\
\hline Faw 1 & Alpha'2.I & $+\mathbf{H}$ & $+\mathrm{H}$ & $+\mathrm{H}$ & $+\mathrm{HI}$ & $+\mathrm{H}$ & $\mathbf{+ H}$ & & & - \\
\hline Faw 2 & Alpha' 2.1 & $+\mathrm{H}$ & $+\mathrm{H}$ & $+\mathrm{H}$ & $+\mathrm{H}$ & $+\mathrm{H}$ & $+\mathbf{H}$ & & & - \\
\hline Faw 3 & Alpha' 2.1 & $+\mathrm{H}$ & $+\mathrm{H}$ & $+\mathrm{H}$ & $+\overrightarrow{\mathrm{H}}$ & $+\mathrm{H}$ & $+\mathbf{H}$ & & & - \\
\hline Faw 4 & Alpha 1.1 & - & - & - & - & - & + & & & - \\
\hline Faw $\overline{0}$ & Alpha 1.1 & - & - & 一 & 一 & - & + & & & - \\
\hline Faw 6 & Alpha 1.1 & - & - & - & - & - & + & & & - \\
\hline Faw 7 & Alpha 1.2 & - & - & - & - & - & - & & & - \\
\hline Faw 8 & Alpha 2.2 & - & - & - & - & 一 & - & + & & - \\
\hline Faw 9 & Alpha 3.1 & - & - & - & - & - & - & & & - \\
\hline Faw 10 & Alpha 1.2 & $+\mathrm{H}$ & $+\mathbf{H}$ & $+\mathrm{H}$ & $+\mathbf{H}$ & $+\mathbf{H}$ & $+\mathbf{H}$ & & & - \\
\hline Faw 11 & Alpha' 1.1 & $+\mathrm{H}$ & $+\mathbf{H}$ & $+\mathrm{H}$ & $+\mathrm{H}$ & $+\mathrm{H}$ & $+\mathbf{H}$ & & & - \\
\hline
\end{tabular}

$-=$ no agglutination; $+=$ complete agglutination in three tubes; $\mathbf{H}=$ held over night; $\mathrm{CA}=$ complete agglutination; $\mathrm{SA}=$ slight agglutination: $\mathrm{ACA}=$ almost complete agglutination.

The organisms were grown in calcium carbonate broth and rabbits injected intravenously on 3 successive days at 5-day intervals. At first cultures heated to $55 \mathrm{C}$. for one hour were used for immunization. Later living cultures were employed. Immunization was carried on over a period of from 2 to 3 months. The loss of 1 or 2 animals through anaphylactic shock led to a preliminary intravenous desensitizing dose being given as routine.

The organisms were grown for 24 hours in calcium carbonate broth, centrifugalized at high speed for half an hour, the supernatant fluid poured off and the sediment resuspended in calcium carbonate broth to make an emulsion of the required density. Clumps were broken up by drawing the sediment in and out through a fine hypodermic needle till an even emulsion was obtained.

In each tube was placed $0.2 \mathrm{c} c$ of suspension and $0.2 \mathrm{c}$ of the diluted serum, giving an ultimate dilution of twice that of the serum 
added. Final dilutions are the ones tabulated. Results were read after incubation in a water bath for one hour at $45 \mathrm{C}$., and again in certain instances after standing over night. The results are shown in table 6.

Beta Strains.-Rabbits immunized against $\beta 2.1$ and $\beta 1.1$ showed a relatively low titer ( $\beta 2.1$ complete $1: 160$ and $\beta 1.1$ complete $1: 320$ ) so that the grouping here cannot be considered perfectly satisfactory. There is however, satisfactory evidence to show that there is no close inter-relationship between any of the beta strains tested with these serums. In each case the homologous strain is agglutinated and heterologous strains are not completely agglutinated even in 1:20 dilution. In one case $\beta 2.1$ strain from the same source as that used for immunizing the $\beta 2.1$ rabbit was completely agglutinated only in a $1: 10$ dilution of the serum. This seems to indicate the presence of immunologic subgroups in the broader groups outlined by the fermentation.

Alpha Prime Strains.-Rabbits were immunized against 3 alpha prime strains, $a^{\prime} 3.1$ and two $a^{\prime} 2.1$ strains with the production of a high titer serum in each case ( $a^{\prime} 3.1$ complete $1: 8,000, a^{\prime} 2.1$ complete $1: 12,000, a^{\prime} 2.1$ complete $\left.1: 12,800\right)$. The $a^{\prime} 3.1$ serum agglutinates all of the heterologous $a^{\prime} 3.1$ strains but fails to agglutinate such strains as $a^{\prime} 5.1$ and $a^{\prime} 1.1$. The $a^{\prime} 2.1$ serums agglutinate all the $a^{\prime} 2.1$ strains and no other organisms in the series with the exception of a single $a 1.2$ and $\boldsymbol{a}^{\prime} 1.1$ strain. These 3 serums in no case agglutinate any of the beta or alpha strains; one might expect to find an $a^{\prime} 2.1$ immune serum of high titer agglutinating a $\beta 2.1$ or $\alpha 2.1$ strain in the lower dilutions; this, however, does not occur, so that one finds no evidence of an immunologic relationship between separate members of each of Brown's 3 types which have identical fermentation reactions. These alpha prime immune serums therefore demonstrate a high degree of specificity in agglutinative power, and there is a striking parallelism between the fermentative grouping of this type and the immunologic grouping. There is, however, a curious apparent loss of specificity when $a^{\prime} 2.1$ emulsions are combined with the various immune serums. Two of these $a^{\prime} 2.1$ strains behaved capriciously at times, emulsions more than one or two days old becoming inagglutinable. The $a^{\prime} 2.1$ immune serum also after storage for 4 months. showed a great diminution in agglutinative power. In every case (12 strains) this class of organism was universally agglutinated by the immune serum, but not by normal human, normal rabbit serum, nor by antityphoid immune rabbit serum, or high titer type 1 antipneumococcus serum; it was, however, occa- 
sionally agglutinated by a 1:20 dilution of normal horse serum but not in higher dilutions. In every case the agglutination of these $\alpha^{\prime} 2.1$ emulsions by the heterologous immune serums occurred in high dilutions of the immune serum. The identification of these $a^{\prime} 2.1$ strains in better known classifications is difficult because the alpha prime group was not formerly recognized as an entity. These organisms, owing to their occasional green production, might have been classed as S. salivarius (Andrewes and Horder) or on account of their hemolytic properties as S. anginosus (Andrewes and Horder). In the case of the $a 1.1$ immune serum the homologous organism was completely agglutinated in a $1: 3,200$ dilution and the $a^{\prime} 2.1$ strain in a 1:5,120 dilution. The immunologic relationship of these strains was of considerable interest so that absorption tests were carrited out, the results of which are shown in table 7.

Alpha Strains.-Rabbits were immunized with two alpha strains -alpha 1.1 and alpha 2.2. The titer of the $a 1.1$ immune serum was 1:3,200 complete and of the a 2.2 serum 1:400 complete (this rabbit was lost through anaphylactic shock before immunization was complete). With these immune serums the same striking parallelism is maintained between the fermentative grouping and the agglutinations. The a 1.1 immune serum agglutinated six a 1.1 strains from various sources and no other strains with the exception of all the $a^{\prime} 2.1$ strains, and a single $a 1.2$ and $a^{\prime} 1.1$ strain. With the lower titer a 2.2 serum, three a 2.2 strains from various sources were agglutinated and no other strains, with the usual exception of the $a^{\prime} 2.1$ strains.

\section{ABSORPTION EXPERIMENTS}

The immune serum chosen for absorption was that produced against the $a 1.1$ strain. This serum was of a suitable titer, and agglutinated the $a^{\prime} 2.1$ strains in high dilutions.

The $a 1.1$ immune serum was absorbed with the homologous strain, with another $a 1.1$ strain, with an $a^{\prime} 2.1$ strain and with the $a 1.2$ and $a^{\prime} 1.1$ strains which showed cross agglutination. The various batches of absorbed serums were tried out with selected emulsions.

The technic adopted for absorption was a modification of that described by Gordon. ${ }^{9}$ A measured amount of broth diluted serun (1/32 of its full titer) was mixed with an equal quantity of heavy emulsion ( $1 \mathrm{cc}=50,000$ million) and placed in a water bath at $45 \mathrm{C}$. for 2 hours with frequent shaking and then left in an incubator over

- Brit. Med. Jour., 1921, I, p. 632. 
night. After this period of contact, the mixture was centrifugalized and the supernatant fluid used for the agglutinations. The method followed for agglitinations was that previously described. The lowest dilution of absorbed serum was therefore $1 / 64$ of the full titer and the final dilution, after addition of the emulsion, $1 / 128$ of the full titer. The results are shown in table 7.

The chief interest of this experiment lies in the relationship revealed between the $a 1.1$ strain and the $a^{\prime} 2.1$ strains. It has already been shown that the various $a^{\prime} 2.1$ strains encountered have been agglutinated

TABLE 7

Ahorption Experiments

\begin{tabular}{|c|c|c|c|c|c|c|c|c|}
\hline Serum & Absorbing Emulsion & Emulsion & $1: 400$ & $1: 800$ & $1: 1,600$ & $1: 3,200$ & $1: 6,400$ & $1: 12800$ \\
\hline \multirow[t]{5}{*}{$\begin{array}{r}\text { Boy 5 } \\
\text { (Alpha } \\
1.1)\end{array}$} & $\begin{array}{l}\text { Not absorbed } \\
\text { Not absorbed } \\
\text { Not absorbed } \\
\text { Not absorbed } \\
\text { Not absorbed } \\
\text { Not absorbed } \\
\text { Not absorbed }\end{array}$ & $\begin{array}{l}\text { Boy } 5 \text { (Alpha 1.1) } \\
\text { Boy } 4 \text { (Alpha' } 2.1) \\
\text { Boy } 22 \text { (Alpha' } 2.1) \\
\text { Faw 1 (Alpha' } 2.1) \\
\text { Boy } 26 \text { (Alpha } 1.1) \\
\text { Faw 10 (Alpha 1.2) } \\
\text { Faw 11 (Alpha' } 1.1)\end{array}$ & $\begin{array}{l}+ \\
+ \\
+ \\
+ \\
+ \\
+\end{array}$ & $\begin{array}{l}+ \\
+ \\
+ \\
+ \\
+ \\
+ \\
+\end{array}$ & $\begin{array}{l}+ \\
+ \\
+ \\
+ \\
+ \\
+ \\
+\end{array}$ & $\begin{array}{l}+ \\
+ \\
+ \\
+ \\
+ \\
+ \\
+\end{array}$ & \pm & \pm \\
\hline & $\begin{array}{l}\text { Boy } 5 \text { (Alpha 1.1) } \\
\text { Boy } 5 \text { (Alpha 1.1) } \\
\text { Boy } 5 \text { (Alpha 1.1) } \\
\text { Boy 5 (Alpha 1.1) } \\
\text { Boy } 5 \text { (Alpha 1.1) } \\
\text { Boy } 5 \text { (Alpha 1.1) } \\
\text { Boy } 5 \text { (Alpha 1.1) }\end{array}$ & 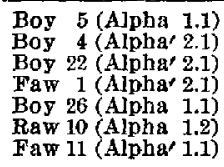 & $\begin{array}{l} \pm \\
\pm \\
\pm \\
\pm \\
\pm \\
+\end{array}$ & 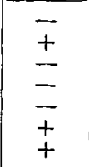 & $\begin{array}{l} \pm \\
\pm \\
\bar{t} \\
+\end{array}$ & $\begin{array}{l}\bar{z} \\
\bar{z} \\
\overline{+}\end{array}$ & $\begin{array}{l}= \\
\bar{z}\end{array}$ & \\
\hline & Boy 4 (Alphar 2.1) & Boy 5 (Alpha 1.1) & Some & Traces & & & & \\
\hline & $\begin{array}{l}\text { Boy } 4\left(\text { Alpha' }^{2} .1\right) \\
\text { Boy } 4 \text { (Alpha' } 2.1) \\
\text { Boy } 4(\text { Alpha' } 2.1)\end{array}$ & $\begin{array}{l}\text { Boy } 4(\text { Alphar } 2.1) \\
\text { Boy } 22(\text { Alpha } 2,1) \\
\text { Faw } 1(\text { Alpha } 2.1)\end{array}$ & $\frac{+}{ \pm}$ & $\begin{array}{l} \pm \\
\pm\end{array}$ & $\underline{\Xi}$ & $\bar{z}$ & $\bar{z}$ & \\
\hline & $\begin{array}{l}\text { Faw 10 (Alpha } 1.2) \\
\text { Faw 11 (Alpha, } 1.1) \\
\text { Faw } 11 \text { (Alpha' } 1.1) \\
\text { Boy 26 (Alpha } 1.1) \\
\text { Boy 26 (Alpha } 1.1)\end{array}$ & $\begin{array}{l}\text { Faw } 10 \text { (Alpha } 1.2) \\
\text { Faw } 11 \text { (Alpha } 1.1) \\
\text { Faw } 10 \text { (Alpha } \\
\text { Boy 26 (Alpha } \\
\text { Boy 5 (Alpha } \\
\text { Boy }\end{array}$ & $\begin{array}{l} \pm \\
\pm \\
\pm \\
\pm \\
\pm\end{array}$ & $\frac{7}{ \pm}$ & \pm & $\underline{\bar{t}}$ & $=$ & \\
\hline
\end{tabular}

$+=$ complete agglutination; $\pm=$ partial agglutination; $-=$ no agglutination.

by all the immune serums in our series, but that they are not agglutinated by normal human, normal rabbit or antityphoid immune rabbit serum, and that the serum produced by these strains is quite specific, agglutinating only $\boldsymbol{a}^{\prime} 2.1$ strains. Table 7 shows that the $a 1.1$ serum, absorbed by the homologous a 1.1 strains has lost agglutinating power for both the $a 1.1$ and $a^{\prime} 2.1$ strains to an almost equal degree; and that the $a 1.1$ serum absorbed by an $a^{\prime} 2.1$ strain shows not only greatly diminished power of agglutinating the $\alpha^{\prime} 2.1$ strains, but also a comparable loss of power for agglutinating the homologous a 1.1 strain. On this basis of absorption therefore these strains are immunologically identical 
-yet there is a great difference, for although the a 1.1 strain will produce an immune serum capable of agglutinating the $a^{\prime} 2.1$ strains in as high dilutions as its homologous strain, the $\boldsymbol{a}^{\prime} 2.1$ strains produce an antiserum quite specific and incapable of agglutinating the $a 1.1$ strains. The position of these $a^{\prime} 2.1$ strains is further considered in the discussion which follows. The position of the single $\alpha 1.2$ and $\boldsymbol{a}^{\prime} 1.1$ strains included in the table is quite different. It is seen (table 6) that these organisms are universally agglutinated like the $a^{\prime} 2.1$ strains; in table 7 it is seen that these strains are capable of absorbing the substances responsible for their agglutination, but that this agglutination is unaffected by the absorption of the a 1.1 immune serum with its homologous strain. The agglutination of these strains must therefore be considered to be due to the production of group agglutinins.

\section{DISCUSSION}

The results of the experiments detailed justify the conclusion that the streptococcal flora in the sputum of patients with bronchial asthma is fairly constant. There is a gradual but slight change of flora (chiefly noticed in the beta types) over long periods ( 2 months; see table 2). It is true that the evidence in table 1 does not support this conclusion, but this experiment was not conducted on a sufficiently extensive scale. The evidence in table 2 and 3 shows a quite conclusive parallelism in the various samples, with certain exceptions in the beta types, when sufficient colonies are picked from the preliminary plates. The flora in these cases is not simple as there were from 8 to 14 different types of streptococcus in each sample of sputum examined. It was thought that the variations in flora encountered in the earlier work might have been due to the choice of particle from the sample of sputum under examination. The results in table 4 show that the flora is remarkably constant in dissimilar particles of sputum in the same sample. The conclusion therefore seems inevitable that apparent variations in flora are due to picking an insufficient number of colonies on the preliminary plates.

Ample confirmation of the complexity of the flora in these cases is contained in the agglutination results in table 6 . It is seen that there is a quite striking parallelism between the grouping by fermentations and by immunologic methods. This is best seen in the result obtained with immune serums $\boldsymbol{a}^{\prime} 3.1, \boldsymbol{a}^{\prime} 2.1, \boldsymbol{\alpha} 1.1$ and $a 2.2$, which agglutinate only organisms of a like type and grouping, with a few exceptions noted earlier. The grouping of the beta types is less clearly 
discernable as the titer of the two immune serums was low; there is an indication, however, that in this type the broad groups based on the fermentation reactions show further immunologic subdivisions. For instance, a heterologous $\beta 2.1$ strain is only slightly agglutinated by the $\beta 2.1$ immune serum, and 2 heterologous $\beta 1.1$ strains are only doubtfully agglutinated by the $\beta 1.1$ immune serum.

The position of Brown's suggested alpha prime type is interesting; the evidence for considering this a distinct type seems ample as the members of this group (with the exception of the $a^{\prime} 2.1$ strains) show no immunologic relationship with either the beta or alpha types of similar fermentation reactions. The $\alpha^{\prime} 2.1$ strains are the most interesting members of the alpha prime group that we have encountered. We have seen that these strains under varying conditions produce radically different appearances in human blood agar, at one time producing green zones (heavy seeding) and at another time producing definite partial hemolytic zones without a shade of green (light seeding). The immunologic relationship of these strains is of still greater interest; all the $a^{\prime} 2.1$ strains encountered were agglutinated by all our immune antistreptococcal serums but not by immune antityphoid serum; the $\boldsymbol{\alpha}^{\prime} 2.1$ immune serums, however, agglutinate only $\boldsymbol{a}^{\prime} 2.1$ strains. These findings are somewhat comparable to those of Kinsella and Swift. ${ }^{10}$ These authors, using the complement fixation reaction as a basis for grouping nonhemolytic streptococci, found that strains of streptococci producing antiserums of wide reacting capacity (extensive cross fixation) will not themselves react with a serum of narrow reacting capacity (fixing only its homologous strain), and a strain which produces an antiserum of narrow reacting capacity will usually react with many serums of a wider reacting capacity than its own. Kinsella and Swift base their explanation of this phenomenon on a consideration of the complexity of the chemical nucleus in various strains. A rabbit injected with a streptococcus of complex chemical nucleus will produce an antiserum capable of fixing this streptococcus and such other strains as contain the same or some of the same structural units. A rabbit injected with an organism containing only one of these units will present an antibody incapable of union with the more complex structures and will fix only streptococci of corresponding simplicity. The $a^{\prime} 2.1$ strains in our series, on this explanation, would represent streptococci of relatively simple nuclei but this simple structural unit is apparently one occurring in the more

in Jour. Exper. Med., 1917, 25, p. 877. 
complex nuclei of the other strains used for immunization of our rabbits. Hence, these types are universally agglutinated but produce an antiserum which agglutinates only this single type. This conception is supported by the absorption experiments conducted with the a 1.1 immune serum and the $\alpha^{\prime} 2.1$ strains. It is found that absorption of this serum with its homologous strain removes not only the agglutinins for that strain, but also, and to the same extent, for the $a^{\prime} 2.1$ strains. It is further found that absorption of the a 1.1 immune serum with an $a^{\prime} 2.1$ strain not only removed the agglutinins for this strain but also, and to the same extent, for the a 1.1 strains. Absorption of the a 1.1 immune serum with the $a^{\prime} 2.1$ emulsion must therefore remove some fraction of the agglutinins without which agglutination of the $a 1.1$ strains cannot occur.

The position of the other alpha prime organisms is more definite. For instance the $a^{\prime} 3.1$ immune serum does not agglutinate the $\beta 3.1$ organisms nor does it agglutinate the single a 3.1 strain present in the series, also the $a^{\prime} 1.1$ strains are not agglutinated by the $\beta 1.1$ antiserum nor by the $a 1.1$ antiserum. It may be assumed then that the members of this alpha prime group possess distinctive cultural and immunologic characteristics.

The immediate practical importance of these observations is related to the method of preparation of vaccines from sputum. With 8 to 14 different types of streptococci in single specimens of sputum, the difficulty of identifying the offending organism is great. It seems to be established that the beta type includes the most actively pathogenic streptococci, yet these organisms are in the minority in the types of sputum which we have studied and the flora of this type is not completely constant in successive samples of sputum from the same source; hence a vaccine including only this type and leaving out the many strains of the other types would seem to be incomplete. The best plan, as far as the streptococcal flora is concerned, appears to be to include all the types which are present, and as far as possible, in the same proportions as they appear in the sputum itself. This can be most simply done by using a 24-hour broth culture of a washed particle of sputum as the basis for the vaccine. Our observations have shown that practically all the organisms are present here and in the same proportion as they are in the particle of sputum itself (table 5). In the preparation of these vaccines, organisms other than streptococci must not be neglected; it has been our experience that these are best isolated on surface plates made from 6-hour broth 
cultures. These seem to develop optimum conditions for the isolation of hemoglobinophilic bacilli which if present may be incorporated in the vaccine.

\section{CONCLUSIONS}

The streptococcal flora in various samples of sputum from the same source, is, in patients with bronchial asthma, fairly constant and quite complex, from 8 to 14 types of streptococci occurring in single specimens.

The streptococcal flora in various particles from the same sample of sputum does not vary.

The simple method of using a 24-hour serum broth culture of a washed particle of sputum as a basis for vaccine preparation seems as efficient as any, the streptococcal flora in such a culture being approximately parallel to that in the sputum itself.

There is, in general, a close parallelism between the grouping of streptococci arrived at through biochemical (fermentation) and serologic (agglutination) reactions.

Certain members ( $\alpha^{\prime} 2.1$ ) of Brown's suggested alpha prime group of streptococci are of particular interest; these $a^{\prime} 2.1$ strains are universally agglutinated by all of our 7 antistreptococcal serums, but produce agglutinins active against their own type of strain only. Absorption experiments indicate that this organism contains a fundamental unit which occurs in each one of the more complicated streptococci used for immunization in our series. 